\title{
Highly Active Fenton-Like Catalyst Derived from Solid Waste-Iron Ore Tailings Using Wheat Straw Pyrolysis
}

\section{Lihui Gao}

China University of Mining and Technology

\section{Lizhang Wang}

China University of Mining and Technology

\section{Shulei Li}

China University of Mining and Technology

Yijun Cao ( $\square$ caoyijuncumt@163.com )

Zhengzhou University

\section{Research Article}

Keywords: Iron ore tailings, Wheat straw, Heterogeneous catalyst, Biochar, Decomposition rate

Posted Date: June 24th, 2021

DOI: https://doi.org/10.21203/rs.3.rs-472422/v1

License: (9) This work is licensed under a Creative Commons Attribution 4.0 International License. Read Full License

Version of Record: A version of this preprint was published at Environmental Science and Pollution Research on January 10th, 2022. See the published version at https://doi.org/10.1007/s11356-021$17168-0$. 
1 Highly active Fenton-like catalyst derived from solid waste-iron ore

2 tailings using wheat straw pyrolysis

$3 \quad$ Lihui $\mathrm{Gao}^{1}$; Lizhang Wang $^{1}$; Shulei $\mathrm{Li}^{2 *}$; Yijun $\mathrm{Cao}^{2,3^{*}}$

1. School of Environment and Spatial Informatics, China University of Mining and Technology, Xuzhou 221116, China

2. National Engineering Research Center of Coal Preparation and Purification, China University of Mining and Technology, Xuzhou 221116, China

3. School of Chemical Engineering and Technology, Zhengzhou University, Zhengzhou 450001, China

Abstract: The pollutants degradation rate of iron ore tailings-based heterogeneous catalysts is the main factor limiting its application. Herein, an iron ore tailings-based Fenton-like catalyst(I/W(3:1)-900-60) with relative fast catalysis rate was constructed by co-pyrolysis $\left(900^{\circ} \mathrm{C}, 60 \mathrm{~min}\right.$ holding time $)$ of iron ore tailings and wheat straw with mass ratio of $3: 1$. With wheat straw blending, the generated I/W(3:1)-900-60 presented a larger surface area $\left(24.3 \mathrm{~m}^{2} / \mathrm{g}\right)$, smaller pore size $(3.707 \mathrm{~nm})$, reduced iron species $\left(\mathrm{Fe}^{2+}\right.$ from magnetic) and a higher catalytic activity $\left(0.0229 \mathrm{~min}^{-1}\right)$ than $\mathrm{I}-900-60\left(1.196 \mathrm{~m}^{2} / \mathrm{g}\right.$, $12.935 \mathrm{~nm}, 0.012 \mathrm{~min}^{-1}$ ) pyrolyzed using a single iron ore tailings under the same pyrolysis conditions. In addition, biochar and iron ore tailings in I/W(3:1)-900-60 were tightly combined through chemical bonding. The optimal catalyst remains active after three cycles, indicating its catalytic stability and recyclability. The good Fenton-like MB degradation efficiency of I/W(3:1)-900-60 was ascribed to the sacrificial role of biochar, as well as the electron transfer between biochar and iron active sites or the 
23 redox cycles of $\equiv \mathrm{Fe}^{3+} / \mathrm{Fe}^{2+}$. This finding provides a facile construction strategy for a 24 highly active iron ore tailings-based Fenton-like catalyst, and thereby had a great 25 potential application in wastewater treatment.

26 Key words: Iron ore tailings; Wheat straw; Heterogeneous catalyst; Biochar; 27 Decomposition rate 


\section{Introduction}

Mining industry is an important activity to extract mineral products around the world. Nevertheless, the mining process always brings a certain degree of pollution. Tailings are solid waste remaining after mining valuable minerals, which are usually disposed at waste dams or landfills that present potential environmental damage (Rico et al. 2008; Kossoff et al. 2014). In March 2020, a miserable accident involving a waste dam occurred when the Yichun waste dam (Harbin, China) for the storage of iron ore tailings collapsed. This accident caused $60,000 \mathrm{~m}^{3}$ of mining tailings disclosing and 3 million $\mathrm{m}^{3}$ of wastewater releasing, leading to 70 kilometers of river pollution and serious economic loss. A number of other tailings dam accidents have occurred in different countries (Batista et al. 2020) . According to statistics (Yi et al. 2020), the accumulated of tailings were about 207 billion tons in China, of which the total amount of tailings produced in 2018 was about 12.11 billion tons. Among all types of tailings, iron ore tailings have the largest amount of production, about 4.76 billion tons, accounting for about $39.31 \%$ of the total tailings production (Huang et al. 2020).

Therefore, it is imperative to explore new technologies for reducing iron ore tailings and their reuse as raw materials to produce value-added products. Recently, a promising application of iron ore tailings is its utilize as adsorbents or catalysts to remove dye compounds (Silva et al. 2011; Augusto et al. 2018), e.g. as a raw/regenerated efficient Fenton and Fenton-like catalysts for wastewater treatment. Given the high iron contents observed in iron ore tailing, it is reasonable to assume that these wastes are good catalysts for Fenton or Fenton-like processes (Augusto et al. 
2018). However, $\mathrm{Fe}^{2+}$ is the effective state for activating the oxidant, while the most common state in iron waste is $\mathrm{Fe}^{3+}$ (dos Santos et al. 2016), and the presence of $\mathrm{Fe}^{3+}$ modifies the degradation rate(reaction time as long as $24 \mathrm{~h}$ ) of substance. Some researchers got significant progress in trying to enhance the pollutant oxidation rate through reducing $\mathrm{Fe}^{3+}$ to $\mathrm{Fe}^{2+}$ (Augusto et al. 2018; de Freitas et al. 2019). Freitas et al achieved good results ( $80 \%$ dye decomposed with $3 \mathrm{~h}$ reaction) for the oxidation of methylene blue when iron ore tailing pretreated in a $\mathrm{CH}_{4}$ atmosphere at $550{ }^{\circ} \mathrm{C}$ for $2 \mathrm{~h}$. Better degradation results could be achieved in case of iron waste pretreatment under reducing atmosphere $\left(\mathrm{H}_{2}, \mathrm{CO}, \mathrm{CH}_{4}\right)$. Biomass could produce reducing gases and compounds during pyrolysis (Williams and Besler 1996; Wang et al. 2010). In our previous paper, we found that a unite mass wheat straw could produce about $5 \mathrm{mg} / \mathrm{g} \mathrm{H}_{2}$ and $18 \mathrm{mg} / \mathrm{g} \mathrm{CH}_{4}$ (Gao and Goldfarb 2019). Therefore, if iron tailings and wheat straw blends were pretreated through pyrolysis to realize the conversion of ferric iron to a low-valent state, it would not only improve the catalytic oxidation efficiency of organic matter, but also realize the resource utilization of wheat straw, which is of great significance.

Therefore, this paper applies methylene blue as a model pollutant to investigate the influence of pyrolysis conditions on the catalyzed degradation rate of pollutants. The pyrolyzed products' morphology, physical-chemical properties, stability and the catalytic mechanism were discussed. The research in this article aims to provides a theoretical basic for iron ore tailing catalyst with high degradation rate.

\section{Materials and methods}




\subsection{Materials}

Iron ore tailings were kindly provided by "Hainan mining" industry, located in Hainan, China. The sample was hematite tailings (T), and ground to $74 \mu \mathrm{m}$ prior to use. Wheat straw selected as biomass because of the high production in China, which was ground in a coffee mill and sieved to a particle size between 100 and $300 \mu \mathrm{m}$ (Gao and Goldfarb 2019). Table S1 showed the characteristics of wheat straw and hematite tailings. Methylene blue was purchased from Aladdin Chemical Reagent Co.Ltd. China.

\subsection{Synthesis of the catalysts}

Hematite tailings and wheat straw mixed with mass ratio 1:1, 2:1, 3:1, 4:1 and 5:1. Then, these mixtures were treated in tube furnace using a heating rate of $10{ }^{\circ} \mathrm{C}$ /min(Wang et al found feedstock pyrolyzed at this heating rate could produce more reducing gas, such as $\mathrm{CO}$ and $\mathrm{H}_{2}$ ) (Wang et al. 2018) until different temperatures (500, $600,700,800$ and $\left.900{ }^{\circ} \mathrm{C}\right)$ for different holding times (30, 45, 60, 90 and $\left.120 \mathrm{~min}\right)$. The obtained catalyst was denoted as I/W(a:b)-T-t, where I iron ore tailings, W wheat straw, $\mathrm{a}: \mathrm{b}$ the mass ratio $(\mathrm{w} / \mathrm{w}), \mathrm{T}$ finally temperature, $\mathrm{t}$ holding time.

\subsection{MB decomposition experiments}

To evaluate the decomposition rate of catalyst produced from iron ore tailings, the bath catalytic experiments were carried out using $0.3 \mathrm{~g}$ of pyrolyzed product in contact with $100 \mathrm{~mL}$ dye solution with initial concentration of $60 \mathrm{mg} / \mathrm{L}$ and $16 \mathrm{mmol} \mathrm{H}_{2} \mathrm{O}_{2}$ under a shaker. $1.5 \mathrm{~mL}$ of solution was pipetted at given time intervals, centrifuged for $1 \mathrm{~min}$ and the dye concentration was detected by a UV-vis spectrophotometer (Unico 
UV-2800) at $664 \mathrm{~nm}$.

To investigate the stability and reusability of catalyst, the optimal pyrolyzed product was reused/recycled several times for the MB decomposition under the same Fenton-like condition.

\subsection{Analytical method}

The phase transformation of ferrochemical group in pyrolyzed solid was analyzed by XRD (Bruker D8 Advance, Germany). The morphology and composition were characterized by SEM-EDX (FEI QuantaTM 250, USA). The textural properties were test by BET (BELSORP-max, Japen). The functional groups of catalysts were investigated by FTIR (Bruker Vertex 80v, Germany). Electron paramagnetic resonance (EPR, Bruker 300E spectrometer, Germany) was applied to test the main reactive oxidative species (ROS) generated in the system. Fe valence and carbon functional group variation of catalysts were characterized by XPS (Thermo Fisher Escalab 250 Xi, USA), and the $\mathrm{C} 1 \mathrm{~s} 1 / 2(284.6 \mathrm{eV})$ was used as the binding energy calibration standard.

\section{Results and discussion}

\subsection{Determination of optimal pyrolysis based on degradation rate}

The pyrolysis preparation mass ratio (iron ore tailings to wheat straw), reaction time and heating rate were fixed at $3: 1,60 \mathrm{~min}$ and $10^{\circ} \mathrm{C} / \mathrm{min}$, respectively, and catalysts were obtained under different pyrolysis temperature. Fig.1(a) showed the comparison of MB removal efficiency versus time and pseudo-second-order kinetic constant $\left(\mathrm{k}_{2}, \mathrm{R}^{2}>0.994\right)$ under different catalysts, which -5 min means the $\mathrm{H}_{2} \mathrm{O}_{2}$ was added after $5 \mathrm{~min}$ adsorption. Only approximately $20 \%$ of MB was removed after $1 \mathrm{~h}$ 
with a kinetic rate of $0.0139 \mathrm{~min}^{-1}$ when the product prepared at $500{ }^{\circ} \mathrm{C}$ used. However, the removal rate and efficiency were substantially improved as the pyrolyzed temperature increased. The best decomposition rate $\left(0.0182 \mathrm{~min}^{-1}\right)$ and efficiency $(74 \%)$ were reached using a catalyst prepared at $900{ }^{\circ} \mathrm{C}$, which was much higher than the generated iron ore tailings catalyst reported by Augusto et al $\left(7.4 \times 10^{-4} \mathrm{~min}^{-1}, 63 \%\right)$ (Augusto et al. 2018). Considering the dye decomposition rate and efficiency, the optimal pyrolysis temperature for synthesizing catalyst was determined to be $900{ }^{\circ} \mathrm{C}$. Setting the pyrolysis temperature as $900{ }^{\circ} \mathrm{C}$ and final holding time as $60 \mathrm{~min}$ and heating rate as $10{ }^{\circ} \mathrm{C} / \mathrm{min}$, the removal efficiency and rate of $\mathrm{MB}$ were investigated by pyrolysis products at different mass ratio. As shown in Fig.1(b), only 10\% MB was removed with a removal rate $k_{2}$ of $0.0120 \mathrm{~min}^{-1}$ when the product prepared by hematite tailings only, indicating that the pyrolyzed product synthesized from iron ore tailings might not be active for dye degradation. While the decomposition efficiency of $\mathrm{MB}\left(k_{2}\right.$ increased from $0.0120 \mathrm{~min}^{-1}$ to $0.0182 / 0.0183 \mathrm{~min}^{-1}$ ) gradually increased when the products made from hematite tailings and wheat straw blends were used as catalyst. This may be due to biomass blends helped to reduce the $\equiv \mathrm{Fe}^{3+}$ to $\equiv \mathrm{Fe}^{2+}$ or low-valent iron (Ellison and Boldor 2021). The mechanism of $\mathrm{H}_{2} \mathrm{O}_{2}$ activation by iron ore tailings based catalyst with $\equiv \mathrm{Fe}^{2+}$ may involve the following reaction processes(Luo et al. 2010). Firstly, a complex assigned as $\equiv \mathrm{Fe}^{2+} \cdot \mathrm{H}_{2} \mathrm{O}_{2}$ may form between the hydrous surface of $\equiv \mathrm{Fe}^{2+} \cdot \mathrm{H}_{2} \mathrm{O}$ and $\mathrm{H}_{2} \mathrm{O}_{2}$ (Eq.(1)), where $\equiv \mathrm{Fe}^{2+} \cdot \mathrm{H}_{2} \mathrm{O}$ represents the reduced sites on the iron ore tailings catalyst surface. The formed $\equiv \mathrm{Fe}^{2+} \cdot \mathrm{H}_{2} \mathrm{O}_{2}$ can produce $\cdot \mathrm{OH}$ by $\mathrm{H}_{2} \mathrm{O}_{2}$ activation, which is ready to decompose and oxidize MB(Eq.(2) and (3)). 


$$
\equiv \mathrm{Fe}^{2+} \cdot \mathrm{H}_{2} \mathrm{O}+\mathrm{H}_{2} \mathrm{O}_{2} \rightarrow \equiv \mathrm{Fe}^{2+} \cdot \mathrm{H}_{2} \mathrm{O}_{2}
$$

$$
\equiv \mathrm{Fe}^{2+} \cdot \mathrm{H}_{2} \mathrm{O}_{2} \rightarrow \equiv \mathrm{Fe}^{3+}+\cdot \mathrm{OH}+\mathrm{OH}^{-}
$$

$$
\cdot \mathrm{OH}+\mathrm{MB} \rightarrow \cdots \mathrm{CO}_{2}+\mathrm{H}_{2} \mathrm{O}
$$

follows:

$$
\begin{aligned}
& \equiv \mathrm{Fe}^{3+}+\mathrm{H}_{2} \mathrm{O}_{2} \rightarrow \mathrm{Fe}^{3+} \cdot \mathrm{H}_{2} \mathrm{O}_{2} \\
& \equiv \mathrm{Fe}^{3+} \cdot \mathrm{H}_{2} \mathrm{O}_{2} \rightarrow \equiv \mathrm{Fe} e^{2+}+\cdot \mathrm{OOH}+\mathrm{H}^{+} \\
& \equiv \mathrm{Fe}^{3+}+\cdot \mathrm{OOH} \rightarrow \equiv \mathrm{Fe}^{2+}+\mathrm{O}_{2}+\mathrm{H}^{+}
\end{aligned}
$$

The formed $\equiv \mathrm{Fe}^{2+}$ subsequently produce $・ \mathrm{OH}$ (Eq.(1)-(3)). Although $・ \mathrm{OH}$ can be generate from $\mathrm{H}_{2} \mathrm{O}_{2}$ when either $\equiv \mathrm{Fe}^{2+}$ or $\equiv \mathrm{Fe}^{3+}$ is present, the generation rates are much faster between $\equiv \mathrm{Fe}^{2+}$ and oxidant (Kwan and Voelker 2002). Although the degradation efficiency for catalysts produced from mass ratio 1:1, 2:1 and 3:1 was equivalent, degradation rate $k_{2}$ values of mass ratio $3: 1\left(0.0182 \mathrm{~min}^{-1}\right)$ and 2:1 $(0.0183$ $\left.\min ^{-1}\right)$ were higher than $1: 1\left(0.0158 \mathrm{~min}^{-1}\right)$. In order to realize the iron ore tailings bulk utilization and construct a catalyst with higher degradation rate, we determined the optimal mass ratio of iron ore tailings to wheat straw was $3: 1$.

Fixing the pyrolysis temperature as $900{ }^{\circ} \mathrm{C}$, the ratio of iron ore tailings to wheat straw as $3: 1$ and heating rate as $10^{\circ} \mathrm{C} / \mathrm{min}$, the optimum holding time was investigated in Fig.1(c). The dye decomposition efficiency of pyrolyzed product was enhanced when the holding time for the synthesis catalyst stretched from 30 to $60 \mathrm{~min}$. However, the degradation efficiency of MB was not significantly improved when the holding time further extended to 90 and $120 \mathrm{~min}$. Interestingly, $k_{2}$ showed a first increasing then 
decreasing trend as the holding time extending, and reached the maximum $\left(0.0182 \mathrm{~min}^{-}\right.$ $\left.{ }^{1}\right)$ when the holding time was $60 \mathrm{~min}$. Thus, $60 \mathrm{~min}$ was the optimal catalyst holding time among those investigated parameters.

To sum up, the relative optimal pyrolysis condition was a blends ratio of 3:1, a pyrolysis temperature of $900^{\circ} \mathrm{C}$ and a holding time of $45 \mathrm{~min}$. $\mathrm{pH}$ as an important factor for the efficiency of Fenton-like reaction, the effect of $\mathrm{pH}$ was investigated in Fig 1(d). We could see that $\mathrm{pH}$ could significantly affect the degradation of $\mathrm{MB}$ in iron ore tailings catalyzed Fenton-like process. As shown in Fig.1(d), the degradation efficiency was relatively low and the $k_{2}$ values were $0.0104 \mathrm{~min}^{-1}$ and $0.0182 \mathrm{~min}^{-1}$ at $\mathrm{pH} 8.1$ and 6.8(did not adjust). While the decomposition of MB gradually increased as the $\mathrm{pH}$ value decreasing and got a highest/fastest degradation efficiency (84\% MB removal, 0.0229 $\min ^{-1}$ ) at around $\mathrm{pH} 3$, which was consistent with previous studies (Hu et al. 2011). The generation of $\cdot \mathrm{OH}$ from $\mathrm{H}_{2} \mathrm{O}_{2}$ is the key step in the entire Fenton-like process, and $\cdot \mathrm{OH}$ catalyzed by iron ore tailings are gradually limited with $\mathrm{pH}$ increasing. The higher $\mathrm{pH}$ with more $\mathrm{OH}^{-}$will cause the reaction (Eq. (7)) to shift back and reduce the activity of Fenton reagent (Zheng et al. 2016), which resulted in a slow decomposition rate of $\mathrm{I} / \mathrm{W}(3: 1)-900-60$.

$$
\mathrm{Fe}^{2+}+\mathrm{H}_{2} \mathrm{O}_{2} \leftrightarrow \mathrm{Fe}^{3+}+\mathrm{OH}^{-}+\cdot \mathrm{OH} \quad \text { Eq.(7) }
$$




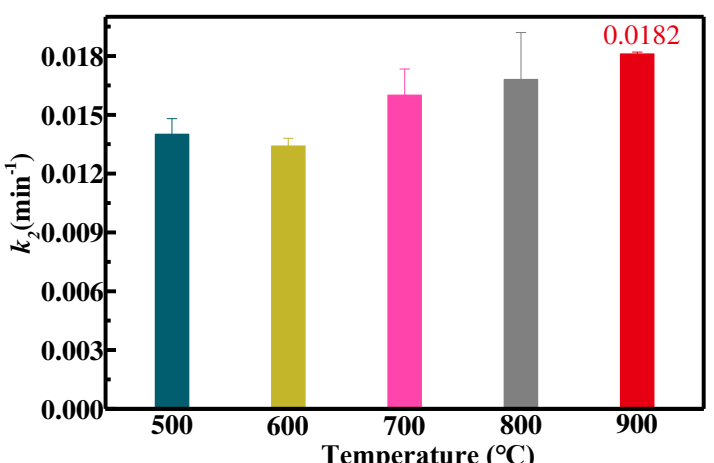

(a) Pyrolyzed temperature
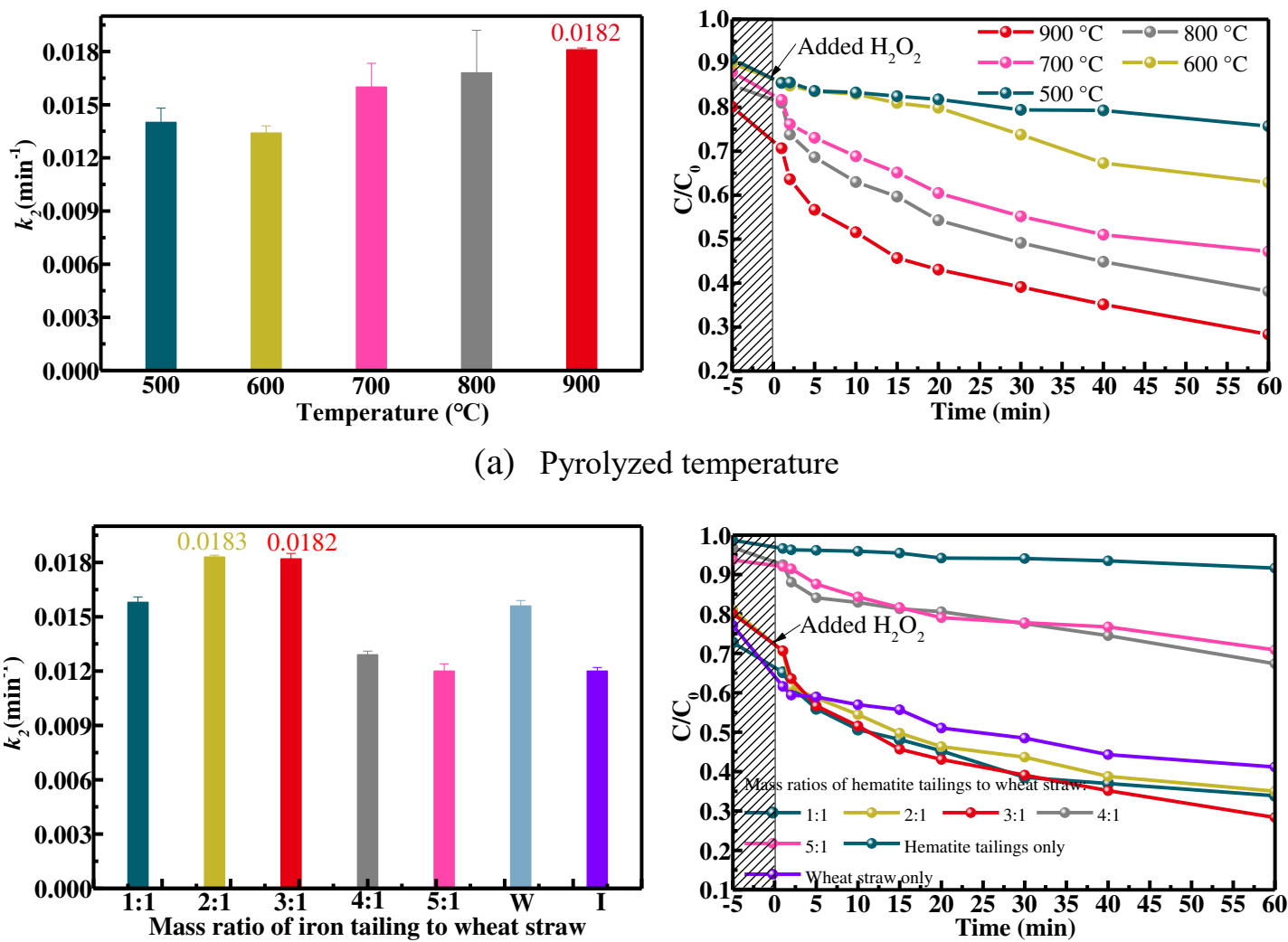

(b) Iron ore tailings to biomass mass ratio
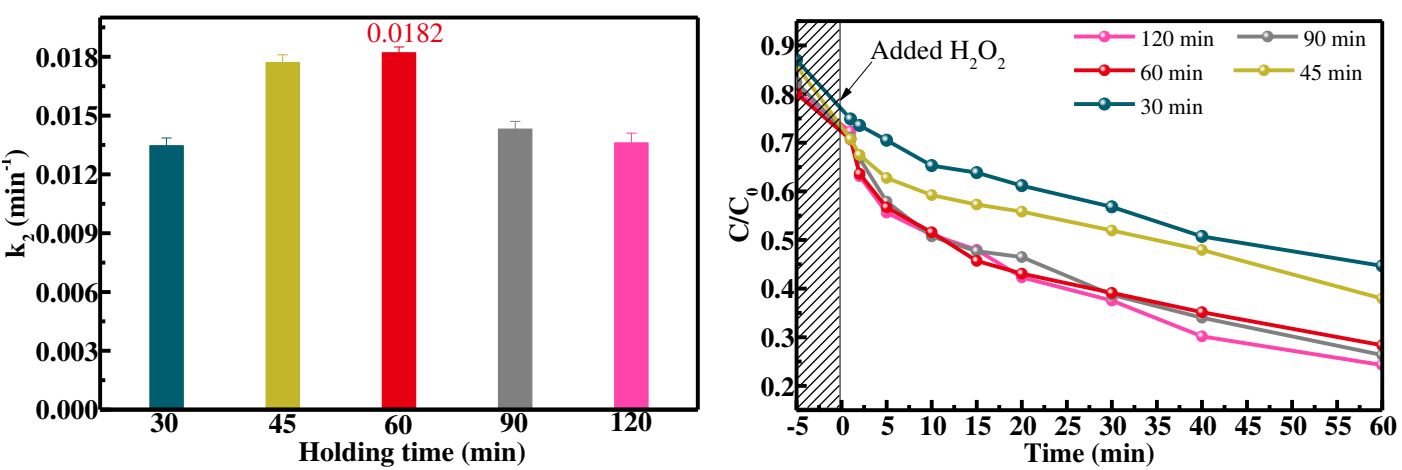

(c) Holding temperature
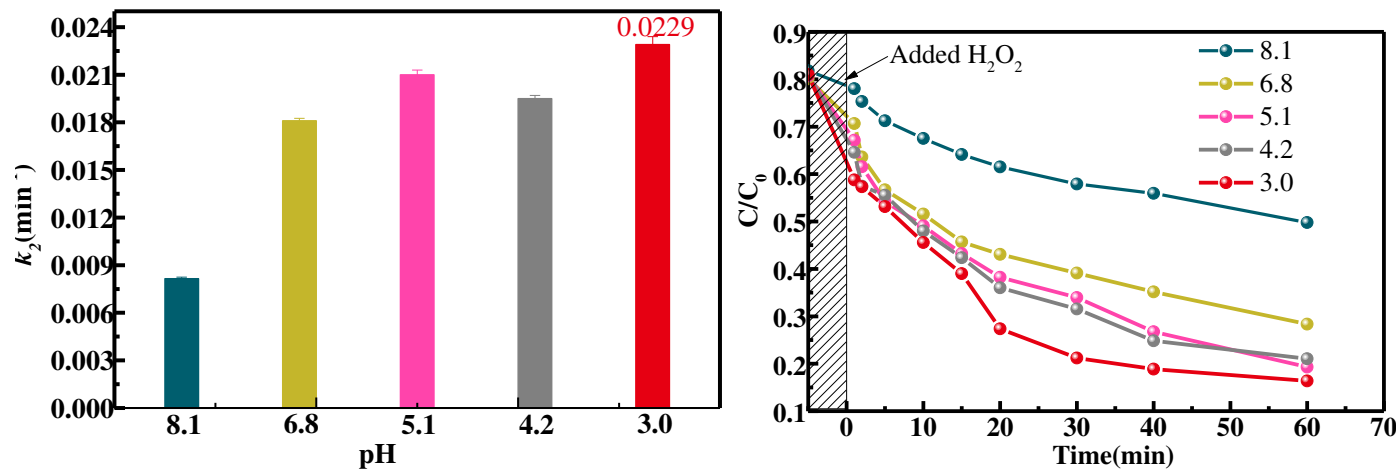

(d) $\mathrm{pH}$ value

Figure 1 Degradation of MB by pyrolyzed product prepared under different conditions 

and I/W(3:1)-900-60, XRD patterns were collected to indicate the phase information of these samples, shown in Fig.2. The XRD pattern of I/W(3:1)-900-60 showed diffraction peaks at $2 \theta=30.3^{\circ}, 43.3^{\circ}, 53.8^{\circ}, 57.5^{\circ}, 68.2^{\circ}$ corresponded to $\mathrm{Fe}_{3} \mathrm{O}_{4}$, which exhibits magnetic characteristics. The peaks of WS-900-60 were noted at $2 \theta=21.8^{\circ}, 26.5^{\circ}, 28.0^{\circ}$, corresponding to $\mathrm{SiO}_{2}$ crystallites. The diffraction peaks of raw iron ore tailings (RT) were attributed to $\alpha-\mathrm{FeOOH}$, and $\alpha-\mathrm{FeOOH}$ was converted to $\mathrm{Fe}_{2} \mathrm{O}_{3}$ when heated to $900{ }^{\circ} \mathrm{C}$ under $\mathrm{N}_{2}$ atmosphere (Zhang et al. 2018). Therefore, only the pyrolysis of iron ore tailings or wheat straw cannot produce a composite with low-valent iron.

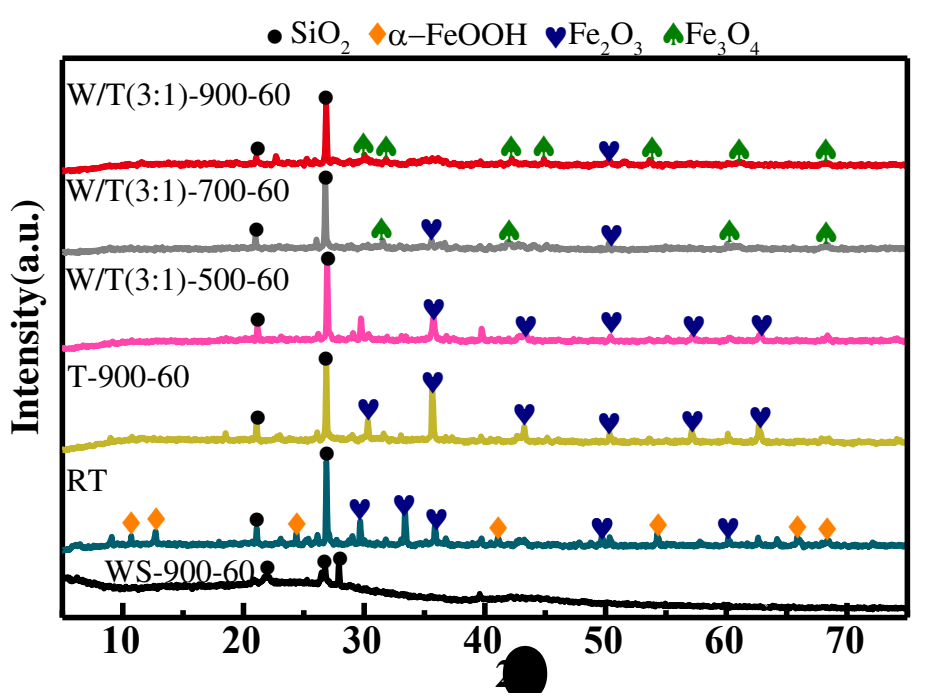

Figure $2 \mathrm{XRD}$ patterns of the raw and prepared samples

Significant transformation of $\mathrm{Fe}_{2} \mathrm{O}_{3}$ to $\mathrm{Fe}_{3} \mathrm{O}_{4}$ was observed at $700-900{ }^{\circ} \mathrm{C}$. When the temperature reached above $700{ }^{\circ} \mathrm{C}$, most of $\mathrm{Fe}_{2} \mathrm{O}_{3}$ peaks disappeared, and the diffraction peaks of magnetite appeared. It can be concluded that $\mathrm{Fe}_{2} \mathrm{O}_{3}$ with trivalent could be reduced to $\mathrm{Fe}_{3} \mathrm{O}_{4}$ during high-temperature pyrolysis. More $\mathrm{Fe}_{2} \mathrm{O}_{3}$ spindles were converted to $\mathrm{Fe}_{3} \mathrm{O}_{4}$ as the temperature increasing. This might due to that there were organic matters such as cellulose, hemicellulose and lignin in wheat straw, and 
these organic matters could be cracked and devolatilized into reducing gas or liquid, such as $\mathrm{H}_{2}, \mathrm{CH}_{4}$, which lead to the ferric iron reduction (Gong et al. 2012; Sharma et al. 2015; Xun et al. 2019; Yunji et al. 2019). In summary, in the process of co-pyrolysis of wheat straw and iron ore tailings, the reducing substances such as $\mathrm{H}_{2}$ or $\mathrm{CH}_{4}$ produced from wheat straw exhibited strong reducibility to reduce iron ore tailings to magnetite. Furthermore, the reduction degree increased as temperature increasing. compared. The surface morphologies of I-900-60 and I/W(3:1)-900-60 were shown in

Fig.S1. The I-900-60 presented a large flaky structure with a flat and non-porous

\begin{tabular}{cccc}
\hline Samples & Surface area $\left(\mathrm{m}^{2} / \mathrm{g}\right)$ & Pore volume $(\mathrm{cc} / \mathrm{g})$ & Average pore size $(\mathrm{nm})$ \\
\hline $\mathrm{I}-900-60$ & 1.1963 & 0.2749 & 12.935 \\
$\mathrm{I} / \mathrm{W}(3: 1)-900-60$ & 24.319 & 5.5875 & 3.707 \\
\hline
\end{tabular}
surface after pyrolysis, mainly because the natural structure of iron ore tailings. In the case of I/W(3:1)-900-60, SEM images showed that most particles had a smaller flake structure, with porous surface. This result indicated that mixing wheat straw promote the formation of a porous and smaller flake structure.

As observed from SEM images, I/W(3:1)-900-60 had a smaller particle than I900-60. $\mathrm{N}_{2}$ adsorption-desorption isotherm was applied to calculate the surface area, pore volume and pore size distribution. As shown in Table 1 and Fig.S2, the average pore size of T-900-60 and I/W(3:1)-900-60 was $12.95 \mathrm{~nm}$ and $3.707 \mathrm{~nm}$. However, the total pore volume was $0.2749 \mathrm{cc} / \mathrm{g}$ and $5.5875 \mathrm{cc} / \mathrm{g}$, respectively. Thus, we can conclude that wheat straw addition increased the pore volume, and decreased average pore size. 
Additionally, although I/W(3:1)-900-60 had a much larger specific surface area(24.319 $\mathrm{cm}^{2} / \mathrm{g}$ ) than I-900-60(1.1963 $\left.\mathrm{cm}^{2} / \mathrm{g}\right)$, its surface area was smaller than those reported iron-load activated carbon adsorbent (300-600 m²/g) (Park et al. 2015; He et al. 2016; Saleh et al. 2017). This result further verified that prepared catalysts from iron ore tailings had weak adsorption ability. Therefore, we speculated the MB degradation by I/W(3:1)-900-60 was due to catalysis instead of adsorption. I/W(3:1)-900-60, with relatively larger surface area and richer pore volume, could provide greater active catalysis sites and increase catalysis performance (Neamţu et al. 2004; Duarte et al. 2012), agreed with the improved MB degradation efficiency catalyzed by I/W(3:1)900-60.

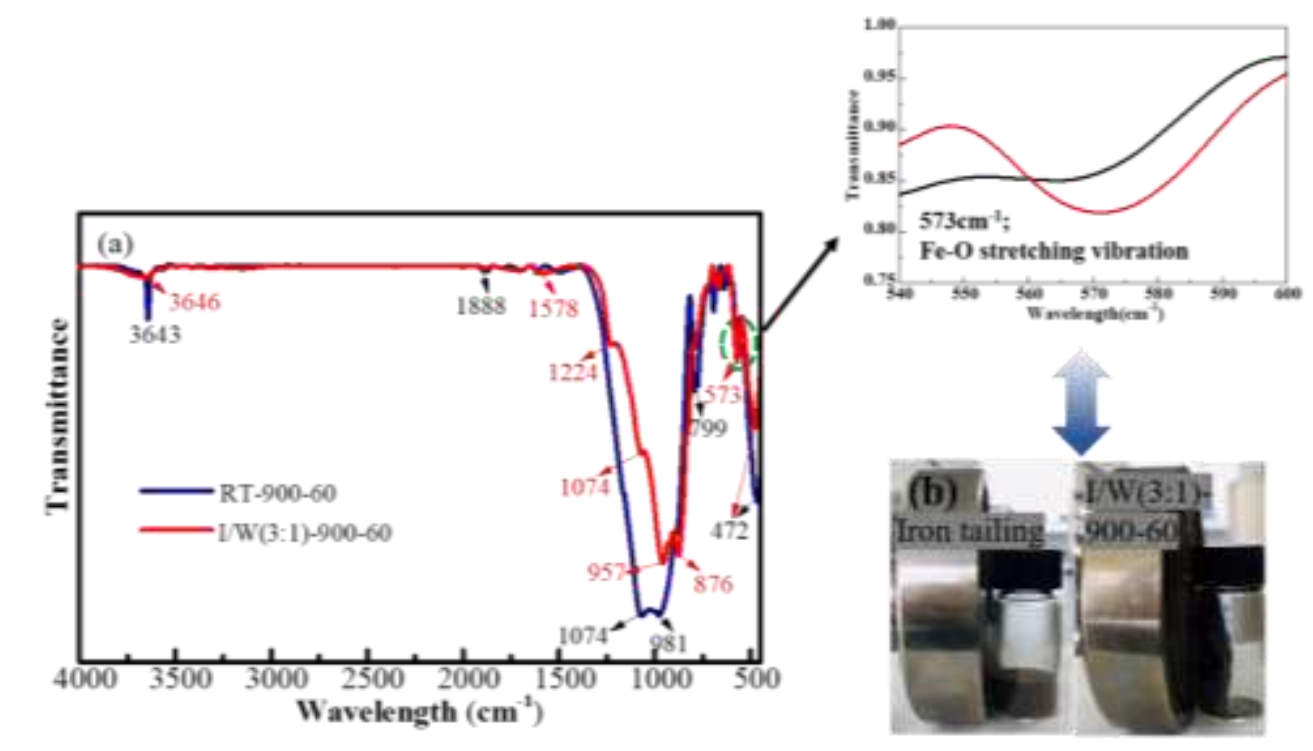

Figure 3 (a) the photos of the products attraction to a magnetic device; (b) FTIR spectra of I-90060 and $\mathrm{I} / \mathrm{W}(3: 1)-900-60$

There is an important question to further discuss that whether composites (wheat straw biochar and iron ore tailings) were simply mixed and exist alone or integrated together. Fig.3(a) showed the catalysts were attracted as a whole by a magnetic device, indicating iron ore tailings and biochar combined as a whole. This binding form is 
beneficial to remove the catalyst from wastewater after reaction. In addition, FTIR spectra was shown in Fig.3(b). The peak at $3643 / 3646 \mathrm{~cm}^{-1}$ was attributed to O-H stretching and bending vibrations (Zhang et al. 2018). Similar I-900-60 peaks were observed in the spectra of both I-900-60 and I/W(3:1)-900-60, including Si-O stretching vibrations of the Si-O-Si, Si-O-Al, Si-O-Fe groups $\left(1074 \mathrm{~cm}^{-1}, 957 / 981 \mathrm{~cm}^{-1}, 472 \mathrm{~cm}^{-}\right.$ ${ }^{1}$ ), although their intensities varied (Doelsch et al. 2003). The silicon content in iron ore tailings was much higher than that in wheat straw (Table S1). Therefore, the intensity of Si-O stretching vibration in I-900-60 was stronger than in the spectrum of I/W(3:1)900-60. Meanwhile, new peaks associated with the $-\mathrm{C}=\mathrm{O}$ and $-\mathrm{C}-\mathrm{H}$ stretching vibration at $1224 \mathrm{~cm}^{-1}$ and $876 \mathrm{~cm}^{-1}$ were observed in the spectrum of $\mathrm{I} / \mathrm{W}(3: 1)-900-60$; these peaks were assigned mainly to the formation of small organic molecules (such as, phenol, furfural, styrene) that are devolatilized, oxidized or creaked from wheat straw during pyrolysis process. In addition, a new peak at $573 \mathrm{~cm}^{-1}$ attributed to an asymmetric Fe-O stretching vibration was observed. It might be caused by loading iron into biochar or $\mathrm{Fe}_{3} \mathrm{O}_{4}$ itself (Yuan and Dai 2014). Therefore, the new bond $\mathrm{Fe}-\mathrm{O}$ on I/W(3:1)-900-60 may indicate the combination of iron and biochar occurred through chemical bonds.

\subsection{The catalyst's stability and reusability analysis}

It is important to evaluate the stability of a heterogeneous catalyst. As illustrated in Fig.S3, I/W(3:1)-900-60 was stable in first three runs and remained high MB degradation efficiency. At the $4^{\text {th }}$ run, the activity of I/W(3:1)-900-60 reduced slightly but the degradation efficiency still higher than $80 \%$, showing the iron ore tailings based 
catalyst can be reused for at least 4 Fenton-like cycles without significant activity loss.

This slightly activity loss is probably due to the small molecules produced during MB degradation occupying part of the active sites, leading to a decrease in catalytic efficiency (Zhang et al. 2018). In addition, the concentration of leaching iron ions after first three runs was measured. As shown in Table S2, the concentration of leached iron was $0.089 \mathrm{mg} / \mathrm{L}, 0.085 \mathrm{mg} / \mathrm{L}$, and $0.093 \mathrm{mg} / \mathrm{L}$, which was only $0.8 \%$ of the iron content in $\mathrm{I} / \mathrm{W}(3: 1)-900-60$. Low leached iron concentration also indicated heterogenous Fenton catalysis was the dominant reaction for MB removal (Gao et al. 2017). Meanwhile, XRD and SEM were applied to examine the structure stability of I/W(3:1)900-60. As illustrated in Fig.S4, compared with fresh catalyst, the crystalline nature and morphology of used I/W(3:1)-900-60 did not change significantly. These results indicated that the cost-effective I/W(3:1)-900-60 was a promising heterogenous catalyst in Fenton-like catalytic degradation of organic wastewater due to its significant stability and reusability.

3.4 Reactive oxidative species and catalysis mechanism
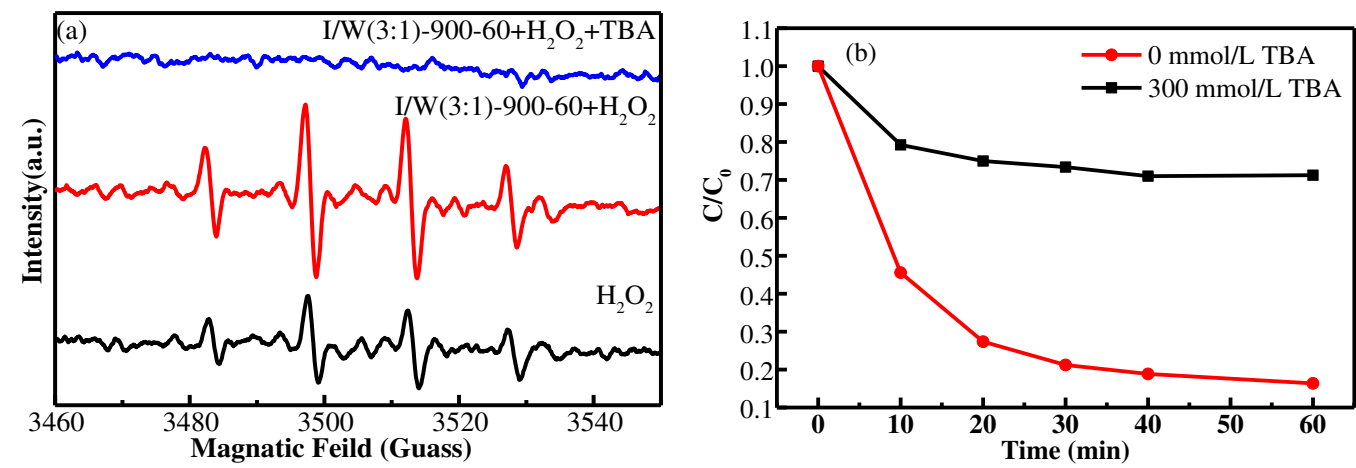

Figure 4 (a)DMPO-ROS adducts generated from I/W(3:1)-900-60 Fenton catalysis reactions at $10 \mathrm{~min}$ (b)influence of radical scavenger (TBA) on the catalytic degradation of MB

ROS produced in I/W(3:1)-900-60 was detected by an EPR spin-trap technique 
with DMPO. Fig.4(a) showed the EPR spectrum of the generated adducts during the 10 min reaction. On the EPR spectrum, there was observed a four-fold peak with an intensity of 1:2:2:1, which was labeled to the DMPO-OH (Yang et al. 2013). However, the four-fold peak was not appeared in the presence of $300 \mathrm{mmol} / \mathrm{L}$ T-Butyl alcohol (TBA, • OH scavenger). Therefore, $\cdot \mathrm{OH}$ was the key ROS produced in I/W(3:1)-90060 catalyzed Fenton-like reactions. Fig.4(b) showed the effect of $\cdot \mathrm{OH}$ on MB degradation. We can see the removal efficiency of MB significantly decreased from $84 \%$ to $29 \%$ in the presence of $300 \mathrm{mmol} / \mathrm{L}$. This result indicated that $\cdot \mathrm{OH}$ played a dominant role in MB degradation in I/W(3:1)-900-60 catalyzed Fenton-like reactions.

The electron exchange between $\mathrm{Fe}(\mathrm{II}) / \mathrm{Fe}(\mathrm{III})$ and $\mathrm{H}_{2} \mathrm{O}_{2}$ can induce the formation of $\cdot \mathrm{OH}$ in the heterogeneous Fenton-like reaction. XPS was applied to analyze the chemical state of iron species on I/W(3:1)-900-60 before and after catalysis reaction. Fig. 5 shows XPS results of Fe $2 p$ in fresh and used I/W(3:1)-900-60. The peaks located at $724.8 \mathrm{eV}$ and $710.9 \mathrm{eV}$ were attributed to $\mathrm{Fe} 2 p_{1 / 2}$ and $\mathrm{Fe} 2 p_{3 / 2}$ states of $\mathrm{Fe} 2 p$ orbits, respectively (Gao et al. 2017; Li et al. 2018). Furthermore, the Gaussian-Lorentzian was applied to decompose these two peaks into 6 different fitting peaks(Ding; et al. 2016). Among them, the fitting peaks located at 719.1 and $729.9 \mathrm{eV}$ attribute to satellite peaks, as well as at 712.0 and $725.3 \mathrm{eV}$ assign to $\mathrm{Fe}^{3+}$, and at 710.6 and $723.8 \mathrm{eV}$ correspond to $\mathrm{Fe}^{2+}$, respectively ( $\mathrm{Li}$ et al. 2018). A summary of deconvoluted peaks' area and the $\mathrm{Fe}^{2+} / \mathrm{Fe}^{3+}$ ratio was presented in Fig.5(a). Apparently, the ratio value of $\mathrm{Fe}^{2+} / \mathrm{Fe}^{3+}$ decreased from 2.18 to 2.17 after reaction, demonstrating only a small amount of $\equiv \mathrm{Fe}^{2+}$ lost electrons and oxidized to $\equiv \mathrm{Fe}^{3+}$ during the catalysis reaction. These XPS 

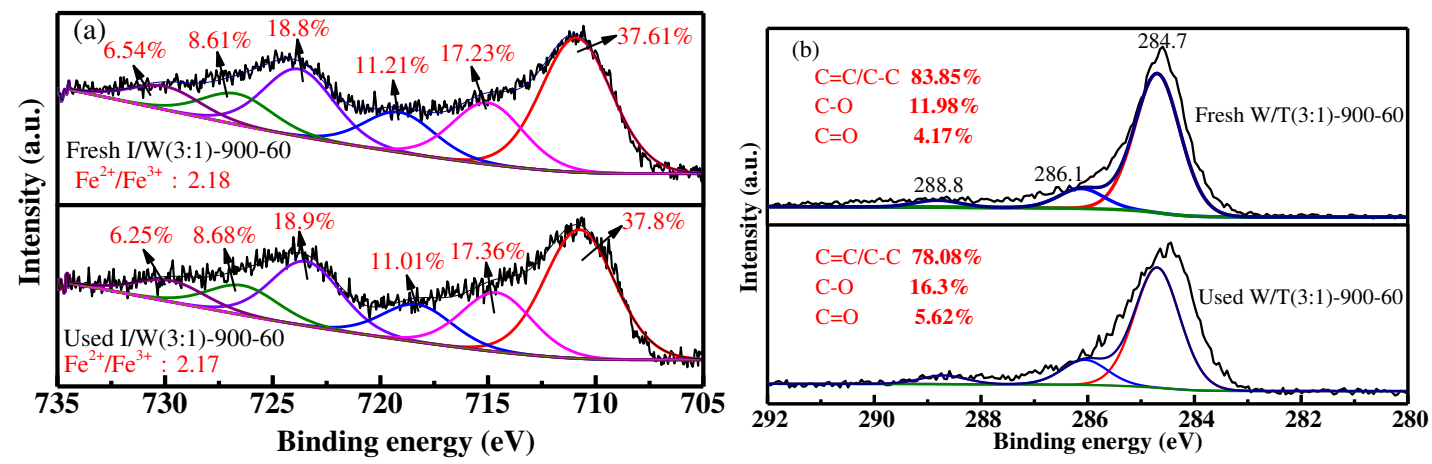

Figure 5 XPS spectra of Fe 2p(a) and C1s(b) on I/W(3:1)-900-60 before and after catalysis reaction

analysis was conducted to investigate the functional groups changes of I/W(3:1)-900fitting peaks with $\mathrm{C}=\mathrm{C} \mathrm{sp}{ }^{2} / \mathrm{C}-\mathrm{Csp}^{3}(284.7 \mathrm{eV}), \mathrm{C}-\mathrm{O}(286.1 \mathrm{eV})$ and $\mathrm{C}=\mathrm{O}(288.8 \mathrm{eV})(\mathrm{Li}$ et al. 2017b). Apparently, compared with the fresh I/W(3:1)-900-60, the relative content of $\mathrm{C}=\mathrm{C} \mathrm{sp} / \mathrm{C}-\mathrm{Csp}^{3}$ carbon was reduced by $5.8 \%, \mathrm{C}-\mathrm{O}$ and $\mathrm{C}=\mathrm{O}$ increased by $4.4 \%$ and $1.4 \%$ after catalysis reaction. This indicates that biochar was oxidized during the Fenton-like process with turning $\mathrm{C}=\mathrm{C} \mathrm{sp} / \mathrm{C}-\mathrm{Csp}^{3}$ carbon to $\mathrm{C}-\mathrm{O}$ or $\mathrm{C}=\mathrm{O}$. Therefore, the recyclability and stability of I/W(3:1)-900-60 catalyst may owe to the existence of biochar which acted as a sacrificial role and limited the oxidation of iron active sites in catalyst. Actually, the biochar can act as a catalyst with electron donor-accepter for the induction of $\mathrm{H}_{2} \mathrm{O}_{2}$ into $-\mathrm{OH}$ or $\cdot \mathrm{OOH}$. The persistent free radicals (PFRs) on the surface of biochar formed by the thermal decomposition of organic compounds can be the reduced and oxidized active sites through electron transfer to form radical species 
surface of biochar have an important influence on the production of $\mathrm{OH}$ by $\mathrm{H}_{2} \mathrm{O}_{2}$ activation (Fang et al. 2014). In addition, the PFRs on the biochar surface lead to the existence of unpaired electrons, which can exchange electrons directly with organic matter, accelerating the MB degradation efficiency (Fang et al. 2013; Yang et al. 2016).

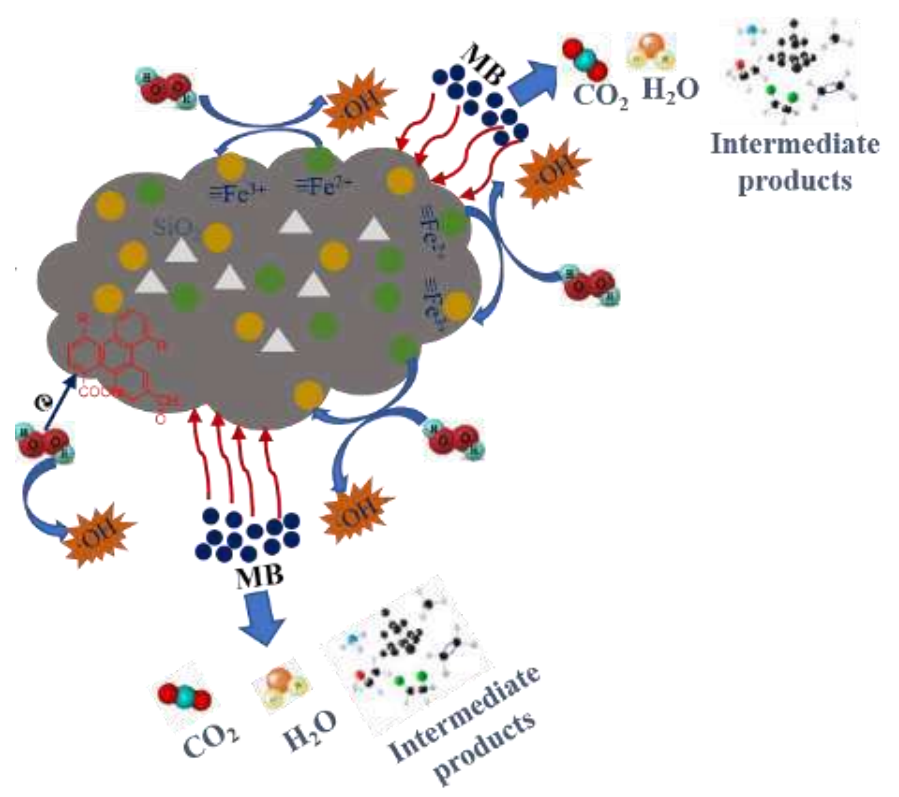

Figure 6 Proposed mechanism for Fenton catalysis reaction of I/W(3:1)-900-60

According to the above analysis results and discussion, the possible Fenton-like reaction mechanism was illustrated in Fig. 6. At the beginning, the MB molecules were adsorbed onto biochar of I/W(3:1)-900-60 from aqueous solution through surface action and pore diffusion. Then, the iron active sites of $\equiv \mathrm{Fe}^{2+}$ and PFRs in biochar simultaneously transfer electron to $\mathrm{H}_{2} \mathrm{O}_{2}$ to generate $\cdot \mathrm{OH}$ for $\mathrm{MB}$ degradation. Moreover, the electron transfer between PFRs and iron active sites or the redox cycles of $\equiv \mathrm{Fe}^{3+} / \mathrm{Fe}^{2+}$ combined results in the enhanced degradation efficiency and rate of heterogenous Fenton-like reaction. Significantly, the stable performance of I/W(3:1)900-60 with good reusability is due to the sacrificial effect of biochar for limiting the oxidation of iron active sites. In addition, the presence of unpaired electrons in PFRs 
contributes to a certain extent to improve the degradation efficiency of pollutants. Table 2 showed the MB decompose rate $k_{2}$ for various Fenton-like catalysts. We can see that I/W(3:1)-900-60(0.0229 $\left.\mathrm{min}^{-1}\right)$ exhibited $a$ higher $k_{2}$ than or comparable to most reported kinetic rate data, which indicates that the co-pyrolysis of iron ore tailings and biomass waste is an effective way to improve the degradation rate/efficiency of iron ore tailings based heterogeneous catalysts. Meanwhile, it is of great significant to realize the resource utilization of iron ore tailings. However, these kinetic rate dates are far less than the degradation rate of homogeneous Fenton catalysis (Gou et al. 2021). Thus, the 349 performance optimization of iron ore tailings-based heterogeneous catalysts based on porous and low-valent iron still needs further studied. Table 2 Comparison of MB removal by Fenton-like methods with different catalysts

\begin{tabular}{cccccc}
\hline Catalyst & $\begin{array}{c}\mathrm{MB} \\
(\mathrm{mg} / \mathrm{L})\end{array}$ & $\begin{array}{c}\text { Catalyst dosage } \\
(\mathrm{g} / \mathrm{L})\end{array}$ & $\begin{array}{c}\text { Time } \\
(\mathrm{min})\end{array}$ & $\begin{array}{c}k \\
\left(\mathrm{~min}^{-1}\right)\end{array}$ & Reference \\
\hline $\mathrm{I} / \mathrm{W}(3: 1)-900-60$ & 60 & 3 & 60 & $2.29 \times 10^{-2}$ & This study \\
$\mathrm{Fe}_{3} \mathrm{O}_{4}$ & 100 & 3 & 30 & $1 \times 10^{-3}$ & (Costa et al. 2008) \\
$\mathrm{Fe}_{3} \mathrm{O}_{4} / \mathrm{H}_{2} / 300 / 1 \mathrm{~h}$ & 100 & 3 & 30 & $4 \times 10^{-3}$ & (Costa et al. 2008) \\
$\mathrm{Fe}_{3} \mathrm{O}_{4} / \mathrm{H}_{2} / 400 / 1 \mathrm{~h}$ & 100 & 3 & 30 & $2 \times 10^{-2}$ & (Costa et al. 2008) \\
$\mathrm{Ferrocene}$ & 10 & 0.372 & 120 & $6.17 \times 10^{-3}$ & (Wang et al. 2014) \\
$\mathrm{Fe}_{3} \mathrm{O}_{4} / \mathrm{rGO}$ & 10 & 0.3 & 120 & $2.6 \times 10^{-3}$ & (Liu et al. 2013) \\
$\mathrm{Fe}_{3} \mathrm{O}_{4} / \mathrm{SiO}_{2} / \mathrm{C}$ & 50 & 1 & 140 & $3.6 \times 10^{-2}$ & (Liu et al. 2013) \\
$\mathrm{Fe}_{3} \mathrm{O}_{4} / \mathrm{CeO}_{2}$ & 100 & 1 & 120 & $2 \times 10^{-2}$ & (Li et al. 2017a) \\
$\mathrm{Fe}_{3} \mathrm{O}_{4} / \mathrm{galic} \mathrm{acid} / \mathrm{GO}$ & 64 & 1 & 200 & $1.2 \times 10^{-2}$ & (Hua et al. 2017) \\
$\mathrm{N}, \mathrm{C} / \mathrm{CuO}-\mathrm{Fe} \mathrm{O}_{3}$ & 75 & 0.1 & 180 & $1.08 \times 10^{-2}$ & (Ren et al. 2019) \\
$\mathrm{FeNi} / \mathrm{C}-300$ & 30 & 1 & 30 & $1.05 \times 10^{-2}$ & (Li et al. 2020) \\
\hline
\end{tabular}

\section{Conclusions}

An iron ore tailings-based Fenton-like catalyst(I/W(3:1)-900-60) with relative fast 
tailings and wheat straw with mass ratio of 3:1. Compared with single pyrolyzed iron ore tailing, the catalytic efficiency and rate of $\mathrm{I} / \mathrm{W}(3: 1)-900-60\left(0.0229 \mathrm{~min}^{-1}, 84 \%\right)$ were considerably enhanced for the decomposition of MB due to the electron transfer between biochar and iron active sites or the redox cycles of $\equiv \mathrm{Fe}^{3+} / \mathrm{Fe}^{2+}$. As a result of the sacrificial effect of biochar, oxidizing $\mathrm{C}=\mathrm{Csp}^{2}$ bonds and limiting the deactivation of iron active sites $\left(\equiv \mathrm{Fe}^{2+}\right), \mathrm{I} / \mathrm{W}(3: 1)-900-60$ showed a good reusability and stability. Moreover, the presence of unpaired electrons in persistent free radicals (PFRs) of biochar accelerated the electron exchange and further enhanced the MB decomposition rate. This work opens up a way to synthesize an iron ore tailings-based Fenton-like catalyst with higher degradation rate, as well as realize the utilization of solid wastes.

\section{Acknowledgement}

L.Gao acknowledges the support of the Fundamental Research Funds for the Central Universities (Grant no. 2020QN37).

\section{Author contributions}

Lihui Gao: Writing-original draft, methodology, Data curation; Lizhang Wang: Writing-Reviewing and Editing; Shulei Li: Investigation, Sample preparation; Yijun Cao: Supervision and Editing.

Availability of data and materials: All data generated or analyzed during this study are included in this published article.

\section{Declarations}

Ethics approval and consent to participate: Not applicable 


\section{References:}

Augusto TDM, Chagas P, Sangiorge DL, Mac Leod TCDO, Oliveira LCA, Castro CS De (2018)

Iron ore tailings as catalysts for oxidation of the drug paracetamol and dyes by heterogeneous Fenton. J Environ Chem Eng 6:6545-6553 . https://doi.org/10.1016/j.jece.2018.09.052

Batista ÉR, Carneiro JJ, Araújo Pinto F, dos Santos JV, Carneiro MAC (2020) Environmental drivers of shifts on microbial traits in sites disturbed by a large-scale tailing dam collapse. Sci Total Environ 738:1-12 . https://doi.org/10.1016/j.scitotenv.2020.139453

Costa RCC, Moura FCC, Ardisson JD, Fabris JD, R.M.Lago (2008) Highly active heterogeneous Fenton-like systems based on $\mathrm{Fe} 0 / \mathrm{Fe} 3 \mathrm{O} 4$ composites prepared by controlled reduction of iron oxides. Appl Catal B Environ 83:131-139

De Freitas VAA, Breder SM, Silvas FPC, Radino Rouse P, de Oliveira LCA (2019) Use of iron ore tailing from tailing dam as catalyst in a fenton-like process for methylene blue oxidation in continuous flow mode. Chemosphere 219:328-334 . https://doi.org/10.1016/j.chemosphere.2018.12.052

Ding C, Zeng Y, Cao L, Zhao L, Zhang Y (2016) Hierarchically porous $\mathrm{Fe}_{3} \mathrm{O}_{4} / \mathrm{C}$ nanocomposite microspheres via a $\mathrm{CO}_{2}$ bubble-templated hydrothermal approach as high-rate and highcapacity anode materials for lithium-ion batteries. J Mater Chem A 4:5898-5908

Doelsch E, Masion A, Rose J, Stone WEE, Bottero JY, Bertsch PM (2003) Chemistry and structure of colloids obtained by hydrolysis of $\mathrm{Fe}(\mathrm{III})$ in the presence of $\mathrm{SiO}_{4}$ ligands. 
Colloids Surfaces A Physicochem Eng Asp 217:121-128 . https://doi.org/10.1016/S09277757(02)00566-6

dos Santos PL, Guimarães IR, Mesquita AM, Guerreiro MC (2016) Copper-doped akaganeite: Application in catalytic Cupro-Fenton reactions for oxidation of methylene blue. J Mol Catal A Chem 424:194-202 . https://doi.org/10.1016/j.molcata.2016.08.034

Duarte F, Maldonado-Hódar FJ, Madeira LM (2012) Influence of the particle size of activated carbons on their performance as fe supports for developing fenton-like catalysts. Ind Eng Chem Res 51:9218-9226 . https://doi.org/10.1021/ie300167r

Ellison CR, Boldor D (2021) Mild upgrading of biomass pyrolysis vapors via ex-situ catalytic pyrolysis over an iron-montmorillonite catalyst. Fuel 291:120226 . https://doi.org/10.1016/j.fuel.2021.120226

Fang G, Gao J, Dionysiou DD, Liu C, Zhou D (2013) Activation of persulfate by quinones: Free radical reactions and implication for the degradation of PCBs. Environ Sci Technol 47:4605-4611 . https://doi.org/10.1021/es400262n

Fang G, Gao J, Liu C, Dionysiou DD, Wang Y, Zhou D (2014) Key role of persistent free radicals in hydrogen peroxide activation by biochar: Implications to organic contaminant degradation. Environ Sci Technol 48:1902-1910 . https://doi.org/10.1021/es4048126

Gao C, Chen S, Quan X, Yu H, Zhang Y (2017) Enhanced Fenton-like catalysis by iron-based metal organic frameworks for degradation of organic pollutants. J Catal 356:125-132 . https://doi.org/10.1016/j.jcat.2017.09.015

Gao L, Goldfarb JL (2019) Solid waste to biofuels and heterogeneous sorbents via pyrolysis of wheat straw in the presence of fly ash as an in situ catalyst. J Anal Appl Pyrolysis 137:96- 
Gong X, Guo Z, Wang Z (2012) Effects of $\mathrm{Fe}_{2} \mathrm{O}_{3}$ on pyrolysis reactivity of demineralized higher rank coal and its char structure. Ciesc J 60:2321-2326. https://doi.org/10.16552/j.cnki.issn1001-1625.2016.06.035

Gou Y, Chen P, Yang L, Li S, Peng L, Song S, Xu Y (2021) Degradation of fluoroquinolones in homogeneous and heterogeneous photo-Fenton processes: A review. Chemosphere 270:112 . https://doi.org/10.1016/j.chemosphere.2020.129481

He Q, Dai J, Zhu L, Xiao K, Yin Y (2016) Synthesis and lead absorption properties of sintered activated carbon supported zero-valent iron nanoparticle. J Alloys Compd 687:326-333 . https://doi.org/10.1016/j.jallcom.2016.06.139

Hu X, Liu B, Deng Y, Chen H, Luo S, Sun C, Yang P, Yang S (2011) Adsorption and heterogeneous Fenton degradation of $17 \alpha$-methyltestosterone on nano $\mathrm{Fe}_{3} \mathrm{O}_{4} / \mathrm{MWCNTs}$ in aqueous solution. Appl Catal B Environ 107:274-283 . https://doi.org/10.1016/j.apcatb.2011.07.025

Hua Y, Wang S, Xiao J, Cui C, Wang C (2017) Preparation and characterization of $\mathrm{Fe}_{3} \mathrm{O}_{4} /$ gallic acid/graphene oxide magnetic nanocomposites as highly efficient Fenton catalysts. RSC Adv 7:28979-28986

Huang D, Yan Q, Xue X, Ren Y, Shen Y (2020) Preparation of Iron Tailings-Based Porous Substrate and Its Application in Synthesis of $\mathrm{Co}_{3} \mathrm{O}_{4}$ Nanowires. Conserv Util Miner Resour 40:64-68

Khachatryan L, Dellinger B (2011) Environmentally persistent free radicals (EPFRs)-2. Are free hydroxyl radicals generated in aqueous solutions? Environ Sci Technol 45:9232-9239 . 
https://doi.org/10.1021/es201702q

Kossoff D, Dubbin WE, Alfredsson M, Edwards SJ, Macklin MG, Hudson-Edwards KA (2014) Mine tailings dams: Characteristics, failure, environmental impacts, and remediation. Appl Geochemistry 51:229-245 . https://doi.org/10.1016/j.apgeochem.2014.09.010

Kwan WP, Voelker BM (2002) Decomposition of hydrogen peroxide and organic compounds in the presence of dissolved iron and ferrihydrite. Environ Sci Technol 36:1467-1476 . https://doi.org/10.1021/es011109p

Li D, Yang T, Li Y, Liu Z, Jiao W (2020) Facile and green synthesis of highly dispersed tar-based heterogeneous Fenton catalytic nanoparticles for the degradation of methylene blue. J Clean Prod 246:1-11

Li K, Zhao Y, Song Ch, Guo X (2017a) Magnetic ordered mesoporous $\mathrm{Fe}_{3} \mathrm{O}_{4} / \mathrm{CeO}_{2}$ composites with synergy of adsorption and Fenton catalysis. Appl Surf Sci 425:526-534

Li S, Gao L, Wen H, Li G, Wang Y (2017b) Modification and application of coking coal by alkali pretreatment in wastewater adsorption. Sep Sci Technol 52:2532-2539 . https://doi.org/10.1080/01496395.2017.1355383

Li W, Wu X, Li S, Tang W, Chen Y (2018) Magnetic porous $\mathrm{Fe}_{3} \mathrm{O}_{4} /$ carbon octahedra derived from iron-based metal-organic framework as heterogeneous Fenton-like catalyst. Appl Surf Sci 436:252-262 . https://doi.org/10.1016/j.apsusc.2017.11.151

Liu W, Qian J, Wang K, Xu H, Jiang D, Liu Q, Yang X, Li H (2013) Magnetically Separable $\mathrm{Fe}_{3} \mathrm{O}_{4}$ Nanoparticles-Decorated Reduced Graphene Oxide Nanocomposite for Catalytic Wet Hydrogen Peroxide Oxidation. J Inorg Organomet Polym Mater 23:907-916 . https://doi.org/10.1007/s10904-013-9863-4 
Luo W, Zhu L, Wang N, Tang H, Cao M, She Y (2010) Efficient removal of organic pollutants with magnetic nanoscaled $\mathrm{BiFeO}_{3}$ as a reusable heterogeneous fenton-like catalyst. Environ Sci Technol 44:1786-1791 . https://doi.org/10.1021/es903390g

Neamţu M, Zaharia C, Catrinescu C, Yediler A, Macoveanu M, Kettrup A (2004) Fe-exchanged Y zeolite as catalyst for wet peroxide oxidation of reactive azo dye Procion Marine H-EXL. Appl Catal B Environ 48:287-294 . https://doi.org/10.1016/j.apcatb.2003.11.005

Park HS, Koduru JR, Choo KH, Lee B (2015) Activated carbons impregnated with iron oxide nanoparticles for enhanced removal of bisphenol A and natural organic matter. J Hazard Mater 286:315-324 . https://doi.org/10.1016/j.jhazmat.2014.11.012

Ren B, Miao J, Xu Y, Zhai Z, Dong X, Wang S, Zhang L, Liu Z (2019) A grape-like N-doped carbon/CuO- $\mathrm{Fe}_{2} \mathrm{O}_{3}$ nanocomposite as a highly active heterogeneous Fenton-like catalyst in methylene blue degradation. J Clean Prod 240:1-10

Rico M, Benito G, Salgueiro AR, Díez-Herrero A, Pereira HG (2008) Reported tailings dam failures. A review of the European incidents in the worldwide context. J Hazard Mater 152:846-852 . https://doi.org/10.1016/j.jhazmat.2007.07.050

Saleh TA, Naeemullah, Tuzen M, Sarı A (2017) Polyethylenimine modified activated carbon as novel magnetic adsorbent for the removal of uranium from aqueous solution. Chem Eng Res Des 117:218-227 . https://doi.org/10.1016/j.cherd.2016.10.030

Sharma A, Pareek V, Zhang D (2015) Biomass pyrolysis - A review of modelling, process parameters and catalytic studies. Renew Sustain Energy Rev 50:1081-1096 . https://doi.org/10.1016/j.rser.2015.04.193

Silva AC, Cepera RM, Pereira MC, Lima DQ, Fabris JD, Oliveira LCA (2011) Heterogeneous 
catalyst based on peroxo-niobium complexes immobilized over iron oxide for organic oxidation in water. Appl Catal B Environ 107:237-244 . https://doi.org/10.1016/j.apcatb.2011.07.017

Wang D, Xiao R, Zhang H, He G (2010) Comparison of catalytic pyrolysis of biomass with MCM-41 and CaO catalysts by using TGA-FTIR analysis. J Anal Appl Pyrolysis 89:171177 . https://doi.org/10.1016/j.jaap.2010.07.008

Wang Q, Tian S, Ning P (2014) Degradation Mechanism of Methylene Blue in a Heterogeneous Fenton-like Reaction Catalyzed by Ferrocenc. Ind Eng Chem Res 53:643-649

Wang X, Zhao H, Li Y, Song Q, Shu X (2018) Study on releasing characteristics of pyrolysis gas products and kinetic analysis of lignite pyrolysis at different heating rates based on TG-MS. Coal Eng 50:140-144

Williams P., Besler S (1996) The influence of Temperature and Heating rate on the Slow Pyrolysis of Biomass. Renew Energy 7:233-250

Xun T, Jianan Z, Xuekai J, Bao W (2019) Catalysis of Fe2O3 for coal char pyrolysis. J WUhan Univ Sci Technol 42:117-120

Yang J, Pan B, Li H, Liao S, Zhang D, Wu M, Xing B (2016) Degradation of p-Nitrophenol on Biochars: Role of Persistent Free Radicals. Environ Sci Technol 50:694-700 . https://doi.org/10.1021/acs.est.5b04042

Yang XJ, Xu XM, Xu J, Han YF (2013) Iron oxychloride (FeOCl): An efficient fenton-like catalyst for producing hydroxyl radicals in degradation of organic contaminants. J Am Chem Soc 135:16058-16061 . https://doi.org/10.1021/ja409130c

Yi L, Mi H, Wu Q, Xia J, Zhang B (2020) Present Situation of Comprehensive Utilization of 

https://doi.org/10.1038/163814b0

Yuan SJ, Dai XH (2014) Facile synthesis of sewage sludge-derived mesoporous material as an efficient and stable heterogeneous catalyst for photo-Fenton reaction. Appl Catal B Environ 154-155:252-258 . https://doi.org/10.1016/j.apcatb.2014.02.031

Yunji P, Yue X, Yisheng C, Shengqiang S, Wuzhen Y, Xueli W (2019) Experimenal study on https://doi.org/10.1016/j.chemosphere.2016.02.001

Zheng J, Gao Z, He H, Yang S, Sun C (2016) Efficient degradation of Acid Orange 7 in aqueous solution by iron ore tailing Fenton-like process. Chemosphere 150:40-48 . Contaminants on N-Doped Graphitic Biochars: Inherent Roles of Adsorption and Nonradical 


\section{Supplementary Files}

This is a list of supplementary files associated with this preprint. Click to download.

- Sl.docx 